\title{
8. O ENSINO JURÍDICO ENTRE CONDICIONAMENTO E CRIATIVIDADE: DESAFIOS PARA SUPERAÇÃO
}

\section{LEGAL EDUCATION BETWEEN CONDITIONING AND CREATIVITY: CHALLENGES FOR AN OVERCOMING}

\author{
Ângela Kretschmann ${ }^{1}$ \\ Leonel Pires Ohlweiler ${ }^{2}$
}

\begin{abstract}
Resumo: após percorrer brevemente a evolução histórica da inserção das Escolas de Direito na sociedade brasileira, observando o contexto fatual no qual foram criadas, realizam uma avaliação crítica das condições para propositura de novos modelos de aprendizagem, e questionam, de modo especial, se é possível propor uma quebra de paradigma do atual modelo imposto pelo Ministério da Educação.
\end{abstract}

Palavras-chave: Educação Jurídica, política estatal, paradigma

Abstract: after go through the historical evolution of the insertion of Law Schools in Brazilian society, noting the factual context in which they were created, perform a critical assessment of the conditions for bringing new learning models, questioning, especially if it is possible to propose a new paradigm regarding the current model imposed by the Ministry of Education.

Keywords: Legal education, government policy, paradigm

\section{Introdução}

A crise do ensino jurídico e da educação jurídica vem sendo discutida há muitos anos. Em breve completaremos 200 anos da fundação das Escolas de Direito de Olinda e São Paulo, e a repetição de matérias e metodologias é algo que vem sendo criticado pelos membros da comunidade acadêmica, tanto docentes quanto discentes, além da própria

\footnotetext{
${ }^{1}$ Doutora em Direito pela Unisinos/RS, Pós-doutora pelo Institut for Information-, Telecommunication- and Media Law (ITM), Münste (Alemanha), professora de Argumentação Jurídica, do Cesuca, e Propriedade Intelectual e Direito e Tecnologia da Informação, na Unisinos. Diretora de Pesquisa no Cesuca. E-mail: angelak@unisinos.br

${ }^{2}$ Doutor em Direito (Unisinos-RS), Professor da disciplina de Teoria Geral do Direito, da Faculdade Inedi, Cesuca; professor do UNILASSALE; Desembargador do Tribunal de Justiça do Rio Grande do Sul. E-mail: leonelo@tj.rs.gov.br
} 
sociedade. O objetivo aqui é, após traçar a evolução histórica da inserção das Escolas de Direito na sociedade brasileira, observando o contexto fatual e legal no qual as faculdades foram criadas e se desenvolveram, realizar uma avaliação crítica das condições para proposta para novos métodos de aprendizagem, e de modo mais particular, se é possível propor uma quebra de paradigma do atual modelo imposto pelo Ministério da Educação.

Por tais razões é que se resolveu promover uma pesquisa que vem agora apenas parcialmente publicada, uma vez que a mesma encontra-se em seu início. O objetivo geral da pesquisa é centrado na análise das condições legais impostas para o ensino jurídico, impostas pelo $\mathrm{MEC}$, as críticas da $\mathrm{OAB}$ e as novas tendências de mudanças que estão sendo implantadas em várias faculdades de Direito no Brasil, avaliando a pertinência das mesmas diante do perfil do aluno digital do século XXI, e das exigências do mercado, entendendo-se nesse contexto tanto as possibilidades de inserção no mercado de trabalho de forma ampla (Judiciário, Academia, profissional liberal, etc.), como também do próprio desejo do aluno.

Outras metas do projeto, específicas, envolvem o esclarecimento dos limites legais impostos pelo Ministério da Educação para os cursos jurídicos no Brasil, a análise das críticas, exigências e atuação da $\mathrm{OAB}$ na autorização e processo de reconhecimento de faculdades de direito no Brasil; a comparação das críticas e condicionantes legais à situação do ensino jurídico ofertado em várias regiões do Brasil; a análise dos instrumentos de avaliação externos acerca da qualidade dos cursos jurídicos ofertados, entre outros aspectos, que não são abordados aqui, justamente pelas restrições impostas quanto ao espaço, e dada a extensão da pesquisa e de seus objetivos, como um todo, sendo possível apresentar apenas brevemente o andamento dos trabalhos e conclusões apenas parciais.

Inicialmente o trabalho de pesquisa volta-se para a identificação do objeto da pesquisa, Ensino Jurídico e Educação Jurídica ${ }^{3}$. A Educação Jurídica tem relação íntima com a genealogia da "formação jurídica" (FREIRE, 1996, p. 37), lembrando de sua distinção, ${ }^{4}$ e as possibilidades de quebra de paradigma diante da atual crise, identificando

\footnotetext{
${ }^{3}$ E nesse sentido surgiu a proposta do livro "Formação Jurídica" lançado pelo Curso de Direito do Cesuca, em 2013, livro que apresenta-se como um convite e um desafio ao educando, e ao educador, advertindo para os perigos de se cair numa rotina jurídica, e lembrando o significado da palavra "formação" para o jurista, vinculado à paidéia grega, palavra também tão cara a Gadamer (KRETSCHMANN, Angela, Org. Formação Jurídica, 1. Ano. Verbo Jurídico: Porto Alegre, 2013. p. 15).

${ }^{4}$ Educação é designação mais ampla do que "ensino", não obstante seu uso muitas vezes ser indistinto. Enquanto a educação envolve todos os processos sociais, éticos, familiares, religiosos, ideológicos, políticos, atravessando "a definição do que o indivíduo paassa a ser a partir de ampla inserção em todos os trâmites da vida social", o ensino é termo a ser utilizado de modo "mais preciso, menos amplo e mais técnico",
} 
as diversas características do ensino que confirmam a prática tradicional do ensino e as dificuldades de mudança. A pesquisa está em seu início e o objetivo inicial é compreender a atual crise do ensino jurídico não apenas da perspectiva dos aplicadores do Direito, ou mesmo da doutrina, mas também a partir dos docentes e dos destinatários do ensino, os discentes.

Após, sob a perspectiva metodológica, a pesquisa desenvolverá atividade de reflexão sobre o sentido desta prática jurídica objeto da pesquisa, a partir dos materiais inicialmente coletados, privilegiando-se a identificação das críticas atuais realizadas, as propostas de mudanças e os maiores obstáculos para as mudanças propostas.

Devido aos limites impostos pela presente publicação não será possível avançar em todos os objetivos propostos pela pesquisa, até porque, a mesma envolve também a análise das atuais tentativas de mudanças já operadas em algumas faculdades, que alguns vêem como casos exemplares de prática jurídica, visando concluir se existe um modelo a ser implantado e que é visado em geral, ou se são casos especiais e que dependam de cada região e corpo discente. De todo modo, alerta-se para o fato de que esta é apenas uma primeira abordagem acerca do problema, dado que a pesquisa está em seu início, e que se pretende publicar outra parcela da mesma na próxima Mostra Científica do Cesuca (novembro de 2014).

\section{Sociedade, Técnica e a Narrativa do Admirável Mundo Novo.}

O texto de Aldous Huxley, de 1932, constitui-se excelente narrativa sobre uma sociedade imaginária na qual o grande lema era: Comunidade, Identidade e Estabilidade. Diversos temas são colocados para proporcionar um amplo debate sobre o modo como o homem vive em sociedade e, no caso do ensino jurídico, como o conhecimento é construído. As pessoas eram divididas em castas: alfa, beta, gama, delta e ípsilon e submetidas a processos de condicionamento, sendo que antes mesmos do nascimento a sociedade institucionalizou um processo de condicionamento biológico.

Toda atividade direcionava-se para construir uma sociedade harmônica, na qual os cidadãos respeitassem as regras sociais e perfeitamente conscientes de pertencerem a uma

envolvendo o processo de aprendizado direcionado e direto, de formação elementar, como a atividade de transmissão de conhecimento dentro de parâmetros predefinidos (BITTAR, 200, p. 12). 
determinada casta e que tinha específicas funções na sociedade, como ocupar postos mais importantes, para a melhor casta, até o desempenho de atividades de menor complexidade.

No entanto, tal desiderato exigia por parte dos dirigentes, todos voltados para o culto do Deus "Ford", a tarefa de banir certas crenças e práticas consideradas inúteis, como ler livros, contemplar a natureza, a religião e a ética...

Como a vida em sociedade não é fácil, e com o fim de sempre manter a estabilidade e harmonia, o autor narra que os cidadãos tinham a possibilidade de consumir uma droga, "sem efeitos colaterais": a soma.

A história de Huxley coloca temas de grande importância para o Direito e o processo de ensino/aprendizagem, como a liberdade, autonomia, o modo de compreensão do próprio mundo e os diversos condicionamentos utilizados pela sociedade dominante, criando-se um ambiente natural no qual certas práticas não são consideradas dignas de uma comunidade civilizada. Os processos de violência para a manutenção do status quo são de outro nível, daqueles utilizados em períodos de opressão.

Bernard Marx, e o nome não é mera coincidência, o personagem principal, sente-se cada vez mais incomodado com o mundo construído pelos grandes dirigentes do Admirável Mundo Novo, desenvolvendo-se a narrativa de modo surpreendente quando, em contato com os habitantes da reserva dos selvagens, encontra Linda e o seu filho John. A partir desse encontro desenvolve-se um texto instigante sobre o choque dos mundos diferentes, um representando o novo, a civilização, o moderno, ou seja, o mundo ideal, marcado pela harmonia e estabilidade. Em contrapartida, de modo questionador, há um mundo de selvagens, representado por John, marcado pelo modo de ser atrasado e ignorante.

Como referido, os diversos temas desta obra de Aldous Huxley possibilitam diversas incursões nas relações entre Direito e Literatura, como já referido em outros textos, de modo a evidenciar que no processo de construção do conhecimento e ensino do Direito, por vezes, tem-se a impressão de que também há a tentativa de construir uma espécie de "Admirável Mundo Novo do Direito". Tal conclusão exsurge em virtude de algumas questões que serão debatidas ao longo deste breve estudo, como a necessidade do modo de ser dogmático de construir uma instância do conhecimento, pode-se dizer, fundado no lema "comunidade, identidade e estabilidade".

Enfim, estas são apenas algumas questões significativas que o livro Admirável Mundo Novo coloca, tratando-se de texto que permite uma gama variada de compreensões 
e leituras, bem como a reflexão entre Direito, Filosofia e Literatura. Um texto provocativo, no qual no início já pontua o seguinte: "Não são os filósofos, mas sim os colecionadores de selos e os marceneiros amadores que constituem a espinha dorsal da sociedade." (Huxley, 2009, p. 29).

\section{Desencantamento e premonição de Huxley aplicada ao Ensino Jurídico}

A ideia de escrever sobre o ensino jurídico tomando como ponto de partida a obra ficcional de Aldous Huxley, “Admirável Mundo Novo", levou em conta o atual estado do debate sobre o ensino jurídico. Paradoxal, porém, simbólico, fato é que a realidade parece espelhar uma ficção jurídica, e a ficção, que deveria se manter na imaginação, parece alcançar uma triste realidade, em especial no Brasil. O texto de Huxley coloca a questão na órbita das obras chamadas de "distópicas", ou seja, que estabelecem uma projeção do futuro, mas de modo pessimista, com críticas sobre as projeções de um mundo atual. Tal forma de observação da literatura é extremamente útil para abordar os problemas da educação, pois o modo como o ensino jurídico é compreendido conduz, por vezes, ao sentimento de pessimismo relativamente ao futuro próximo, caso mantido o atual sistema.

A ligação faz sentido diante das críticas atuais no sentido de que os cursos jurídicos, que deveriam preparar o jurista para a vida real, nada mais estariam fazendo do que treinar estudantes para as provas da $\mathrm{OAB}$, e que esses alunos mais não estariam fazendo do que efetivamente decorar informações e automatizar o estudo por meio de exercícios repetitivos de provas anteriormente aplicadas, como se costuma fazer para exame de direção do Detran, por exemplo, para carteira de motorista. Seria também, ao final e ao cabo, a própria "instituição social do homogêneo, que violenta o diverso" (WARAT, 2005, p. 111) - e onde o homogêneo social dos juristas seria o "senso comum teórico" trabalhado 10 anos antes pelo autor.

No entendimento de Luiz Alberto Warat, o senso comum teórico dos juristas:

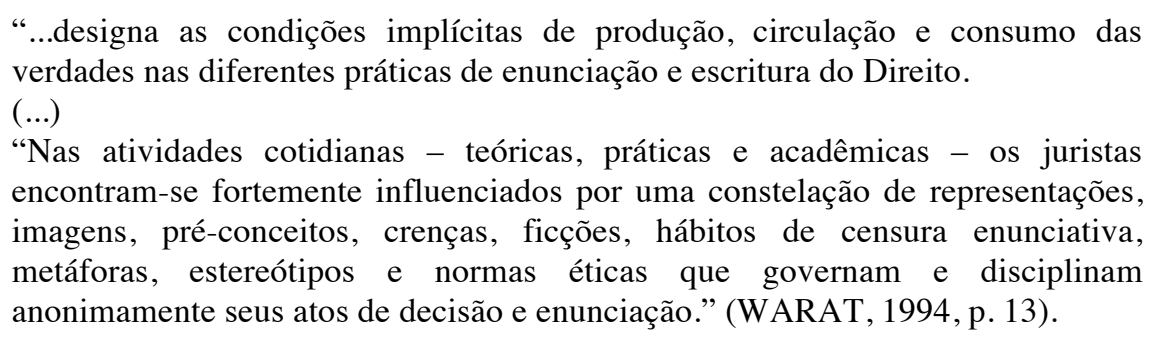

O ensino jurídico deve dar-se conta de que não pode construir-se como prática exatamente para dar continuidade a estes processos dominantes da linguagem que 
consagram condições implícitas de um sistema de exclusão social e de desigualdades. Este é um dos grandes questionamentos: o atual ensino nos Cursos de Direito possibilita o quê para os alunos? O desenvolvimento de uma postura crítica em relação a este conjunto de hábitos e pré-conceitos que alimentam o imaginário social dominante? Perpetuar estas convenções de sentido, prontas para permitir respostas dogmáticas?

E agora o que importa é a vontade de singularizar, a vontade de autonomia, a "anomalia selvagem", que ao contrário do "selvagem" de Huxley, é capaz de trazer o inesperado e suplantar o imaginário instituído, consagrado e permanente, enraizado e encapuzado pelo sentido do poder das instituições que oficializam uma linguagem e oferecem a "proteção" do poder.

É nesse sentido que o livro de Aldous Huxley contribui com este estudo, pois apresenta um notável desenvolvimento do ensino condicionado, descartando qualquer possibilidade de reflexão crítica. $\mathrm{O}$ mundo do ensino, por vezes, desenvolve o aspecto simbólico das ideias institucionalizadas no universo ficcional de Houxley: "Não há civilização sem estabilidade social. Não há estabilidade social sem estabilidade individual." Em um dos diálogos iniciais do texto entre o Diretor e um dos estudantes, houve o questionamento sobre as vantagens do "Processo Bokanovsky", sendo que a resposta foi imediata, típico das certezas influenciadas pelo senso comum: "O Processo Bokanovsky é um dos principais instrumentos de estabilidade social. Um dos principais instrumentos de estabilidade social." E para reforçar sua resposta, o Diretor de Fecundação citou o lema plenatário: “Comunidade, identidade, estabilidade.”(Huxley, 2009, p. 33). O ensino jurídico, nas suas práticas cotidianas, mas fundados em "lemas planetários", mais pós-modernos, também institucionaliza na sua linguagem comum um processo de estabilidade, criando o que Luiz Alberto Warat denomina de "cumplicidade semiológica" (WARAT, 1994, p. 14), pois cria-se a necessidade de pertencer àquele grupo, adotando o princípio da produção em série, como na obra de Huxley.

É justamente o contrário da proposta de liberdade e autonomia de Warat, que persegue a coragem do indivíduo de ser criativo, coragem de ir contra a homogeneidade instituída, e de perder as garantias significativas das supostas garantias das instituições (Warat, 1995, p. 113).

Essa espécie de premonição de Huxley atinge de modo bastante intenso o Ensino e a Educação Jurídica, pois oferece uma ideia também de ruptura, podendo ser traçado um paralelo entre as inúmeras rupturas pelas quais a história humana passou, mudando 
conceitos de trabalho, de riqueza, poder e saber. E com as rupturas, ocorrem saltos históricos. O problema é que esses saltos estão se tornando cada vez mais desconhecidos de todos.

A hipótese que aqui se apresenta, com o auxílio do livro de Aldous Huxley, é que há uma perda de memória em relação a fatos históricos que produzem um salto invertido, com reflexos bastante peculiares no ensino e educação jurídicos. A ausência de memória tem relação com as mudanças que ocorrem em ritmo jamais visto, tanto no plano científico quanto no plano econômico, geográfico, econômico, etc. As pessoas parecem em transe, desorientadas, surpresas a cada dia, e são tantas as novidades e surpresas que o passado fica cada vez mais distante, e também mais distante a percepção de pertencimento a alguma história ou tradição.

Mais uma vez, é relevante o entendimento de Luiz Alberto Warat sobre este tema:

\begin{abstract}
As significações não deixam de ser um instrumento de poder. Aceitando-se que o Direito é uma técnica de controle social não podemos deixar de reconhecer que seu poder só pode se manter estabelecendo-se certos hábitos de significação. Existe portanto um saber acumulado - difusamente presente nas redes dos sistemas institucionais - que é condição necessária para o exercício do controle jurídico da sociedade. Com isto, estamos ressaltando as dimensões políticas dos sistemas de enunciação. Quando esse sistema é autoritário precisa solidificar artificialmente as relações sociais, modelando e centralizando a produção de sentido, deixando inelutáveis a marca do Estado, fabrica então um sistema de sublimações semiológicas que servem para criar versões do mundo que nos abstraem da história. (WARAT, 1994, p. 15)
\end{abstract}

O condicionamento educacional é uma das formas de fixar esse processo de abstração da história, pois se cria um imaginário segundo o qual a reflexão sobre os processos da história é dispensável, afinal a programação tecnológica determina o porvir dos estudantes. É interessante como essa questão surge no texto de Huxley quando o Sr. Forter refere:

\footnotetext{
- Nós também predestinamos e condicionamos. Decantamos nossos bebês sob a forma de seres vivos socializados, sob a forma de Alfas ou de Ípsilons, de futuros carregadores ou de futuros - ia dizer "futuros Administradores Mundiais", mas corrigindo-se completou: futuros Diretores de Incubação. (Huxley, 2009, p. 41).
}

Países em que o PIB cresce a nível jamais visto a desorientação acaba em euforia, mas em países onde a crise avança, também cresce a depressão, e na visão de De Masi (2014, p. 713) até mesmo a ausência de um modelo interpretativo da crise causa opressão. Daí porque o autor informa "a opressão de um não-modelo, nos torna indefesos diante do 
medo da guerra, das epidemias, dos imigrantes, da superpopulação, da poluição, da violência, das quedas da bolsa, da solidao...," pois também a ideologia já teve emitido um atestado de óbito:

\begin{abstract}
Junto com as ideologias, desapareceram os líderes amados como Gandhi, venerados como Pio XII, estadistas como Juscelino Kubitschek, temidos como Stálin: personalidades carismáticas, capazes de oferecer sólidos pontos de referência às gerações passadas. Talvez nenhum dos governos mais recentes, à exceção do chinês, tenha conseguido elaborar e realizar os planos socioeconômicos como os de Stálin e Roosevelt ou Getúlio Vargas. Hoje, refutadas as ideologias, mortos os mestres, perdidos os líderes, a qual modelo, a qual ensinamento, podemos recorrer, nós desorientados do terceiro milênio? (DE MASI, 2014, p. 714).
\end{abstract}

A incerteza de tudo nos é oferecida pela multiplicidade de hipóteses, e assim se rediscute quando começa a vida, quando começa a morte, o que é relação estável, o que é família, o que é estado vegetativo, engenharia genética, nanotecnologia, tecnologias de informação, há uma sucessão de perguntas e para cada uma milhares de respostas. Isso quase que poderia levar uma manada indistinta a correr em direção de qualquer coisa que indicasse constância, harmonia, segurança, equilíbrio, homogeneidade - como o imaginário instituído do direito oferece.

E assim, ao mesmo tempo em que se busca a fuga da homogeneidade, busca-se também o conhecimento da tradição, pois como alertou Warat, os encarregados de aplicar as leis, produtores e professores das escolas de Direito - todos forjam uma realidade imaginária (do senso comum) - que é um mundo de faz-de-conta, instituído com naturalidade, considerada simplesmente "imprescindível para a própria configuração do Direito na sociedade" (WARAT, 1995, p. 120). Aliás, forjar esta realidade social labora com um processo de condicionamento, muito bem retratado na obra de Huxley nas palavras do Diretor: “- É esse - interveio sentenciosamente o Diretor - é esse o segredo da felicidade e da virtude: amarmos o que somos obrigados a fazer. Tal é a finalidade de todo o condicionamento: fazer as pessoas amarem o destino social de que não podem escapar." (HUXLEY, 2009, p. 44).

Os que lidam com ensino e a educação jurídica, portanto, possuem esta tarefa de sair do senso comum, caso contrário tão-somente desempenharão uma atividade voltada para ocultar, em última análise, o componente político de investigação de verdades, como aduz Luiz Alberto Warat, pois este campo simbólico constitui-se no espaço que canoniza imagens e crenças: 
Por conseguinte se canonizam certas imagens e crenças para preservar o segredo que escondem as verdades. O senso comum teórico dos juristas é o lugar do secreto. As representações que o integram pulverizam nossa compreensão do fato de que a história das verdades jurídicas é inseparável(até o momento) da história do poder. (WARAT, 1994, p. 15).

Mais uma vez é útil a distinção feita pelo autor entre doxa e episteme, pois como no próprio Direito, no senso comum do ensino jurídico a epistemologia não passa de uma "doxa politicamente privilegiada", isto é, por trás dos métodos de ensino existe uma mentalidade difusa de controle e submissão ao senso comum e "a ordem epistemológica de razões é substituída por uma ordem ideológica de crenças que preservam a imagem política do Direito e do Estado." (WARAT, 1994, p. 16). O questionamento profundo do ensino no Direito, considerando o que até o momento foi exposto, não pode deixar de questionar qual a concepção de ciência dotada e o seu valor social.

É claro que este processo educacional de construção do imaginário não ocorre de forma violenta, ao menos não com o emprego da força física, mas de forma simbólica, erigindo-se um imaginário de sentido, no qual os estudantes são jogados. Como na obre de Huxley, desde tenra idade, este processo é realizado - aqui com condicionamentos físicos. A passagem do condicionamento no texto deste autor é significativa para compreender o modo de funcionamento do sentido comum teórico. Descreve-se que o método de eletrificação consistia em energizar uma parte do assoalho no qual se encontravam livros e flores. Quando se aproximavam do canto onde estavam os livros sofriam o choque! Igual procedimento adotava-se em relação às flores, cujo objetivo era criar um sentimento de ódio, pois não se poderia permitir que pessoas de castas inferiores desperdiçassem o tempo da comunidade com livros, além de provocarem o descondicionamento. Em relação às flores, tinham o grave defeito de serem gratuitas, não estimulando a atividade de nenhuma fábrica (Huxley, 2009, p. 55-56).

O ensino do Direito deve ser capaz de ultrapassar esta tentação do condicionamento, eis que utilização de manuais, por exemplo, descontextualizados, desestimula a pesquisa, tendo-se a impressão de que o estudante entra em choque quando se depara com a necessidade de construir pesquisa em livros densos e tratados ou repertórios de jurisprudência. Mesmo que de forma inconsciente, funciona como se os livros que debatem questões complexas fossem capazes de provocarem o "descondicionamento". Por outro lado, o condicionamento proporcionado pelo paradigma liberal-individualista, determina a construção de um conjunto de ficções voltadas para a capacidade de simbolizar os indicativos jurídicos que protegem a propriedade, quer dizer, 
somente as coisas com valor econômico, pois como refere Huxley, "as flores são gratuitas”. Não é por acaso que nesse mundo nem tão imaginário, admirável, venera-se o "Nosso Ford".

\section{As tentativas legais de rompimento com a dogmática tradicional}

Há algum tempo, em quase todos os ramos do Direito, questiona-se a crise na qual estão imersos os diversos institutos jurídicos, sendo que os debates sobre o ensino jurídico não poderiam ficar imunes, pois ainda hoje é possível identificar em algumas práticas o pendor para o dogmatismo, vislumbrado nos seguintes termos: "apresenta-se como a tentativa de construir uma teoria sistemática do direito positivo, sem formular nenhum juízo de valor sobre o mesmo, convertendo-o em uma mera ciência formal." (WARAT, 1995, p. 16). Trata-se, portanto, do modo de compreender a própria construção do conhecimento jurídico, considerando as influências do positivismo jurídico, fundado na premissa sobre a possibilidade de conceituar o Direito por meio da sistemática descrição de regras jurídicas, sem formular juízos de sentido.

Aliás, este aspecto é criticado de forma qualificada por Ronald Dworkin, pois o jusfilósofo parte do entendimento segundo o qual não é possível responder à pergunta o que é o Direito no campo da mera descrição fática ou fincado em algum fundamento externo, como alude Sthephen Guest (GUEST, 2010, p. 16). Constitui-se, portanto, questão crucial no ensino jurídico. Na medida em que diversos temas, de variados ramos do Direito devem ser trabalhados com alunos, o que não pode ocorrer é esta atividade de passividade epistemológica, ensinar, por exemplo, Direito Administrativo, Direito Penal, Direito Civil, como que simplesmente descreve fatos e agrega dispositivos legais. Por esta razão, o pensamento de Dworkin também é significativo para o ensino, pois ao longo de sua obra desenvolveu a chamada atitude interpretativa do Direito, isto é, um modo de compreensão voltado para as práticas sociais que conformam o próprio Direito. Ultrapassa-se com vantagens o modelo neutro imposto pelo dogmatismo, eis que na linha do complexo entendimento de Dworkin, não há como divorciar da compreensão o seu caráter deontológico, cujo conteúdo funda-se no princípio de que as pessoas devem ser tratadas com igual respeito e dignidade (GUEST, 2010, p. 17).

Os diversos conceitos jurídicos, dessa forma, não podem ser obtidos com a descrição de regras tout court. A título de exemplo, em um dos últimos livros de Ronald 
Dworkin, ao examinar questões sobre a verdade, questiona as condições de possibilidade para mostrar que uma concepção de igualdade ou liberdade está correta em relação a outras concepções rivais. Alude a importância de perceber que as pessoas partilham determinados conceitos e isto ocorre porque partilham determinadas práticas sociais, surgindo divergências em virtude de haver interpretações diferentes destas práticas. Tais conceitos são conceitos interpretativos (Dworkin, 2011, p. 18). Claro que a afirmação segundo a qual o Direito é um conceito interpretativo não é isenta de críticas e polêmicas, mas indica a necessidade de repensar algumas práticas educacionais no campo jurídico, pois é preciso construir um saber capaz de lidar com estas divergências. Uma prática educacional voltada também para o mundo da vida do direito, eis que o Direito é uma prática interpretativa, dotada de um conjunto de objetivos e princípios que lhe conferem sentido, mas não um sentido abstrato, obtido por meio de conceitos semânticos, mas um propósito construído no horizonte de sentido das relações intersubjetivas e projetado na história institucional da comunidade jurídica a que pertence.

Aliás, desde 1994 há um rompimento com o ensino tradicional do Direito. A partir, portanto, do final do século XX, com a Portaria 1.886 do MEC tratou-se de recolocar na tradição jurídica a importância das matérias que demandam reflexão crítica e que exigem um pensar crítico do aluno, disciplinas de base, disciplinas distribuídas em um "eixo fundamental" que acolheu matérias consideradas propedêuticas, de ensino básico, constituintes de uma formação mínima para a passagem ao eixo profissional. Depois a Resolução n. 9/2004, do Conselho Nacional de Educação reforçou a intenção de uma formação humanística (mas também enciclopédica), que trouxesse as condições para uma consciência crítica.

Essa política nacional que surge a partir da década de 1990, preocupada com o estabelecimento de projetos político-pedagógicos para cursos de direito vai buscar romper com esse ensino do Direito que vinha assolado por um ensino codificado, dogmatizado, formalizado, "fruto do legalismo e do exegetismo - devido à sua vinculação com a visão positivista dominante na ciência do Direito" (Rodrigues, 2008, p. 152), cursos que se nasciam e cresciam fortemente vinculados ao imaginário instituído por conceitos de crescimento econômico e liberalismo, já superados.

O Ministério da Educação passou a exigir professores qualificados, porém, essa qualificação não garante que a formação jurídica do estudante será alterada. Pode melhorar, mas pode não ser suficiente para superar os obstáculos desse saber arraigado a 
uma tradição ultrapassada. E pode inclusive reforçar o poder dessa concepção ultrapassada. Se o professor, qualificado ou não, se mantém desconectado da realidade social, obviamente nada mudará no ensino e muito menos na educação jurídica.

A Portaria $\mathrm{n}^{\circ} .1 .886$, de 30 de dezembro de 1994 fixava "as diretrizes curriculares e o conteúdo mínimo do curso jurídico" e afirmava: Art. $1^{\circ} \mathrm{O}$ curso jurídico será ministrado no mínimo de 3.300 horas de atividades, cuja integralização se fará em pelo menos cinco e no máximo oito anos letivos..$^{5}$ Já a Resolução 09/2004, veio estabelecer as diretrizes curriculares para os Cursos de Direito, indicando um modelo substituto ao trazido pela Portaria 1.886, pautado por conteúdos fundamentais (economia, sociologia, filosofia, ciência política, psicologia, ética, antropologia e história); profissionalizante (direito constitucional, direito administrativo, direito tributário, direito penal, direito civil, direito empresarial, direito do trabalho, direito internacional e direito processual), mantendo o Estágio Supervisionado e as Atividades Complementares, transformando a Monografia de final de Curso em Trabalho de Conclusão, obrigatório.

Como pode ser percebido, o objetivo já era tentar escapar da prisão de um ensino excessivamente positivista, vinculado a vários dogmas da modernidade e do cientificismo moderno. A análise realizada por Luiz Alberto Warat sobre as etapas do método dogmático constitui-se questão importante para indicar o modo de ser de algumas práticas no ensino do Direito e que precisam ser ultrapassadas. Conforme refere expressamente o autor:

\begin{abstract}
A primeira etapa compreende a época da conceitualização dos textos legais. Esta se baseia no pressuposto de que não há mais direito que o ordenamento jurídico estabelecido, através das leis, validamente ditadas e vigentes. Deste modo, a dogmática jurídica se vincula diretamente com o positivismo, limitando sua função à interpretação da lei através do método denominado exegético que, inclusive, para alguns autores, determina a denominação desta etapa como exegética, (WARAT, 1995, p. 17).
\end{abstract}

Percebe-se no âmbito das práticas educacionais que, por vezes, trabalha-se em sala de aula com os estudantes dentro desta primeira etapa, pois o sentido do instituto jurídico está na própria lei, como se houvesse uma lei com sentido em si, na linha do que inclusive tem sido criticado por Lenio Luiz Streck (2004, p. 95). O estudante é jogado para o "mundo dos conceitos", o que traz consequências danosas para o futuro profissional do Direito, não apenas por construir seu imaginário no horizonte de sentido dos conceitos semânticos, no campo da abstração metafísica, mas por formar operadores com baixa

\footnotetext{
${ }^{5}$ Já a Resolução CNE CES 02/2007 trouxe nova imposição de carga horária mínima para o curso de Direito (em 3700 horas).
} 
capacidade de compreender as divergências jurídicas do mundo da vida e o conjunto das práticas sociais que alimentam este campo do conhecimento.

Como aduz Luiz Alberto Warat esse modo de ensinar desemboca no formalismo, convertendo-se o Direito como algo que se limita a reproduzir um conteúdo vigente, olvidando a importante tarefa de justificar! No entanto, existe a segunda etapa do método dogmático, segundo menciona o autor:

\begin{abstract}
A segunda etapa é propriamente a da dogmatização jurídica, da fixação dos dogmas jurídicos, da elaboração das preposições, categorias e princípios obtidos a partir de conceitos jurídicos, extraídos dos textos legais. Obtém-se os princípios gerais (o casamento é indissolúvel, os contratos devem ser cumpridos), quer dizer, os dogmas que marcam a pauta diretora, que ordenam teoricamente o funcionamento do conjunto de normas legais vigentes para qualquer situação jurídica através dos institutos ou construções jurídicas.(WARAT, 1995, p. 18).
\end{abstract}

Aqui igualmente percebe-se o ensino fundado nessas bases, pois o espaço da sala de aula é um campo de fixação de saberes prontos, cunhados para serem trabalhados de forma abstrata, principalmente com base na dedução. Os princípios obtidos diretamente do texto são princípios gerais, quer dizer, nada mais representam do que a onipotente vontade do legislador, cuja aplicação representa materializar uma autorização legal. Por fìm, a terceira etapa do saber dogmático consiste na sistematização, pois não é suficiente conceituar, dogmatizar, é preciso fechar as condições de possibilidade do conhecimento (WARAT, 1995, p. 19).

Como alterar este estado de coisas?

Um ensino, então, pautado por uma base pluridimensional, traz melhores condições de desenvolvimento de um potencial crítico, de modo que o aluno enfrente as mais inusitadas situações que apenas uma sociedade democrática poderia impor. A própria democracia fomenta a necessidade de juristas críticos e que deixem de servir ao tradicional poder instituinte do imaginário social. $\mathrm{O}$ aluno deve receber condições para mostrar-se apto a criticar e propor mudanças em relação ao poder vigente.

Mas a imposição de novas diretrizes para o ensino jurídico continuou a buscar solidificar esse caminho para uma renovação, de modo a construir condições de possibilidade de um saber não fundado nas bases do dogmatismo. Com isso, em 2010 foi emitido o Parecer CONAES n. 4, de 17 de junho, ditando critérios de criação e trabalhos do Núcleo Docente Estruturante, determinando que o Núcelo constitui um relevante 
indicador da qualidade de um curso de graduação, capaz de conduzir a um diferencial em relação ao comprometimento da instituição com a qualidade do ensino.

Na sequência, foi emitida ainda a Resolução n. 1, de 30/05/2012, estabelecendo as diretrizes nacionais para a educação em direitos humanos, que trata do uso de concepções e práticas educativas fundadas nos Direitos Humanos e em seus processos de promoção, proteção, defesa e aplicação na vida cotidiana e cidadã de sujeitos de direitos e de responsabilidades individuais e coletivas (art. $2^{\circ}$.), com a clara finalidade de promoção da educação para a mudança e a transformação social, fundando-se nos princípios da dignidade humana; da igualdade de direitos; do reconhecimento e valorização das diferenças e das diversidades; da laicidade do Estado; da democracia na educação; transversalidade, vivência e globalidade; e sustentabilidade socioambiental.

E finalmente, tivemos a Resolução n. 2, de 15/06/2012, estabelecendo a Educação Ambiental, respeitando a autonomia da dinâmica escolar acadêmica, que deve ser desenvolvida como uma prática educativa integrada e interdisciplinar, contínua e permanente em todas as fases, etapas, níveis e modalidades, não devendo, como regra, ser implantada como disciplina ou componente curricular específico (art. $8^{\circ}$.), sendo tal criação uma faculdade, entretanto, para os cursos de graduação, extensão e pós-graduação (parágrafo único do artigo $8^{\circ}$.).

Essas determinações não são destinadas exclusivamente ao ensino jurídico, mas a ensino superior em geral. Todos os cursos foram obrigados a integrarem em suas grades o ensino dos direitos humanos e do direito ambiental. O ensino deverá dar conta de um aluno apto a rechaçar o "autoritarismo de uma didática tradicional", assim como deverá imporse contra o ensino oficial que discrimina qualquer abordagem anômica dita como "não científica" (Machado, 2009, p. 161).

O que é possível perceber, entretanto, é que por mais que sejam impostas por Lei mudanças nas estruturas dos Cursos, nada efetivamente tende a mudar se essa mudança não partir dos destinatários e daqueles que estão diretamente envolvidos com o dever de mudança. Afinal, a crise não é um privilégio do ensino jurídico, isso já foi também constatado, e está aí porque as partes envolvidas no processo e na crise insistem em permanecer em uma situação de conforto - que felizmente, agora, já não é mais tão confortável. 


\section{A abertura para o novo no ensino jurídico brasileiro: o aluno autor}

O descontentamento é generalizado, e em parte a deterioração da educação das massas pode ser decorrente do excessivo marketing e da voracidade por diplomas, como informa CUNHA (2006, p. 25). A revisão do discurso jurídico, como nos revela WARAT (2004, p. 346), indica a necessidade de que se perceba os vínculos nódicos que o vinculam ao poder, de forma a constituir-se como espécie de manifestação do encobrimento e que merece ser desconstruído.

O desencantamento sofrido pelas Escolas de Direito é atravessado pela Semiótica do Poder denunciada por WARAT (2004, p. 346-347), e que tende a paralisar as iniciativas de rechaço a qualquer atitude desconstrutivista do que está aí como paradigma do verbo e da ação. Aliadas ao discurso do poder estão as demandas de uma nova geração, cansada de tanto bloqueio perante a porta da Lei, consegue agora atravessá-la com o apoio de políticas públicas de acesso ao ensino superior (Fies, Prouni, por exemplo), e que tentam, ainda que em desalinho, também proporcionar acesso ao conhecimento, mas que têm no máximo conseguido alcançar um acesso a um diploma, como se tivessem o mesmo e indistinto significado. E deveriam ter, mas não têm, dadas às fragilidades das demandas, dadas às fragilidades das ofertas, dadas às fragilidades do próprio ser que busca ou tenta buscar, e do que oferece, ou tenta oferecer, aprendizado.

E a crise é tanta que já se vislumbra a desnecessidade dos antigos Mestres, como se no desespero pela busca do saber jurídico o próprio aluno tivesse condições de galgar completamente sozinho as diversas etapas do conhecimento jurídico. Fato é que a alguns prodígios esse feito não pode ser negado, mas generalizar a desnecessidade de mestres já parece ser leviano e irresponsável, para dizer o mínimo.

Afinal, há que se ter em mente que, não obstante a diversidade territorial, geográfica, também há uma diversidade histórica e cultural imensa, em vários aspectos digna de aplauso, porém, em outros, digna de preocupação e especial atenção principalmente por instituições que desejam ofertar ensino e educação jurídicos. Generalizar em termos de ensino jurídico ou educação jurídica é o mesmo que negar o acesso universal ao ensino.

Há que se ter muito cuidado na oferta desse ensino que é engolido por uma massa ansiosa e com muito apetite. A ausência da crítica pode levar à aceitação da oferta de um ensino que nada propõe, não ousa transformar, não oferece e nem tem como oferecer 
liberdade pelo desenvolvimento da autonomia. Um ensino massificado, que não presta atenção no aluno, e na sua realidade social, pode bem confundir-se com a proposta do processo de Bukanovsky, como uma forma de controle social, indicado por Huxley: "O Processo Bukanovsky é um dos principais instrumentos da estabilidade social" (Huxley, 2009, p. 32). E adiante: “ - Estabilidade - disse o Administrador. Não há estabilidade social sem estabilidade individual” (Huxley, 2009, p. 82).

Ao contrário da ilusão proposta pela obra de Huxley, que propõe o condicionamento como segredo para o "sucesso" e "felicidade" (o que infelizmente lembra as exigências para aprovação em determinados concursos e prova da $\mathrm{OAB}$ ), bom lembrar aqui que, consideradas as atuais condições do ensino que se deseja enfrentar, e em paralelo à obra de Huxley, a sabedoria que aqui se trata é aquela apresentada por Aristóteles (1999, p. 20): as pessoas se tornam o que são pela prática - o justo se torna justo pela prática da justiça, assim como um músico torna-se grande artista praticando e tocando a cítara, e um escritor se torna um bom escritor praticando a escrita, e o mau escritor não tem o hábito nem de pensar, quiçá de escrever.

\footnotetext{
...lo aprendemos haciéndolo; por exemplo, nos hacemos constructores construyendo casas y citaristas tocando la cítara. Así también practicando la justicia nos hacemos justos, practicando la templanza, templados, y praticando la fortaleza, fuertes. (...)

Si no fuera así, no habría ninguna necesidade de maestros, sino que todos serían de nacimiento bueno o males. Yl lo mismo ocurre con las virtudes (...)

No tiene, por consiguiente, poca importancia el adquirir desde jóvenes tales o cuales hábitos, sino muchísima, o mejor dicho, total. (1103, b, 5-25).
}

No mesmo sentido, a prática e o hábito de escrever sem sentido, de ler apenas títulos de notícias, de digitar palavras apenas abreviadas, traz como resultado uma escrita sem sentido, um texto inócuo. Da mesma forma que quem toca mau um instrumento, e não exerce a prática da boa música, irá produzir o mesmo resultado. No campo jurídico também, escritos sensacionalistas costumam ganhar força, e seus autores muitas vezes andam em círculos, sem conseguir se desprender do vício do sensacionalismo vão que é buscado, e bem assim, sem conseguir produzir um texto que efetivamente acrescente algo novo ao estado atual do conhecimento.

Isso tudo significa que a busca da sabedoria requer muito trabalho. Não se nasce pronto, como diz Aristóteles, e se assim, fosse, também os Mestres não seriam necessários. A análise do ensino jurídico considerando a obra de Aldous Huxley pode parecer exagerada, dada a extravagância das profecias que o autor apresenta. Todavia, justamente 
devido a tais exageros parece o momento de traçar esse paralelo, uma vez que se chega a um momento limite nas críticas ao ensino jurídico.

Sem dúvida alguma, se os cursos jurídicos tiverem por interesse a produção em série de profissionais em uma espécie de plataforma mecanicista, conseguirão produzir, como propõe o livro de Aldous Huxley, uma geração de profissionais domesticados, padronizados, preparados exclusivamente para dar as repostas que o sistema exige, e de modo dócil, o que nos aproxima muito do livro de Huxley, quando relata o modo como os jovens eram condicionados ao afastamento dos livros e da reflexão, como inclusive já mencionado.

Elas crescerão com o que os psicólogos chamavam de ódio "instintivo" aos livros e às flores. Reflexos inalteravelmaente condicionados. Ficarão protegidas contra os livros e a botânica por toda vida". ${ }^{6}$

Um paralelo entre a realidade atual e uma obra de ficção como a proposta de Huxley pode auxiliar na percepção de que efetivamente chega-se a um ponto limite em que é necessário reaprender a ensinar, e reaprender a aprender, e ensinar, sempre, para a liberdade, que é, no fundo, a verdadeira preocupação de Aldous Huxley quando escreveu o livro, uma vez que vivia exatamente em meio a uma época de surgimento de grandes regimes totalitários. Se for para inovar, que seja em direção à defesa da preservação da autonomia do sujeito.

Essa questão de apreender a reaprender também remete para uma reflexão interessante realizada por Hans Georg-Gadamer, por ocasião de uma palestra proferida em 19.05.1999, e que determinou a publicação de um pequeno texto intitulado La Educación es Educarse (GADAMER, 2000), no qual o fislósofo inicialmente destaca que no processo de ensino uma das questões fundamentais é saber conversar, eis que a educação só ocorre por meio do diálogo. O tema do diálogo, inclusive, ocupou boa parte de sua obra, desde Verdade e Método, destacando-se que dialogar é estar disposto para tal, ver no outro alguém com quem conversar. Por esta razão, Gadamer refere que no processo de educação o professor também se educa, no sentido de participar de um diálogo de forma aberta $\left(\right.$ GADAMER, 2000, p. 15) ${ }^{7}$.

\footnotetext{
${ }^{6}$ HUXLEY, Aldous. Admirável Mundo Novo. Trad. Vidal de Oliveira. São Paulo: Globo, 2009. p. 55.

${ }^{7}$ No entendimento do autor "la educación es así un processo natural que, a mi parecer, cada cual acepta siempre cordialmente procurando entenderse com los demas.” (GADAMER, 2000, p. 35-36).
} 
Para criticar a forma atual de ensino, o filósofo refere como exemplo o ensino de língua estrangeiras, referindo que no seu entendimento há uma relação demasiadamente unilateral e não uma compreensão recíproca (GADAMER, 2000, p. 29), sendo que uma das possibilidades de alterar este estado de coisas é institucionalizar o modo de ensino pela pergunta. Aliás, o ensino erigido nestas bases de privilegiar a capacidade de perguntar, ao invés da absorção de conteúdo, com certeza, contribui para aumentar o nível de autonomia criativa do estudante em relação às práticas sociais.

A preservação da autonomia não levará o aluno muito longe, mas a condição de autonomia que chama a si na luta por um espaço criativo é que efetivamente poderá constituir e/ ou quebrar um novo "mito do bom selvagem" na voz do aprendiz jurídico, para que possa constituir-se como instituinte de si mesmo, ciente de sua voz e seu significante no contexto de um processo de amadurecimento para a vida jurídica.

É por esta razão que Luiz Alberto Warat coloca a importância dos direitos humanos e da democracia, não como conjunto abstrato de leis, tratados, ou do próprio texto da Constituição Federal, mas uma particular e específica postura política frente à vida:

\begin{abstract}
...a gênese de um processo de transformação da ordem simbólica e das instituições socialmente estabelecidas, onde a autonomia dos desejos seja básica, assim como o cuidado com o planeta que nos abriga. Numa palavra, os direitos humanos como ativo fermento de uma auto-alteração da sociedade. Quero dizer com isso que, sob seus diversos aspectos, a tarefa política dos direitos humanos inscreve-se diretamente no esforço para a instauração de uma sociedade autônoma. Seria, em suma, o combate às condições instituídas da heteronomia. A eco-cidadania.(WARAT, 1997, p. 69).
\end{abstract}

Neste aspecto, o âmbito do ensino e da educação pode constituir-se como espaço público de transformação de uma ordem simbólica normatizada por instituições socialmente estabelecidas, contribuindo para a construção de um estudante com autonomia crítica. É claro que em tempos pós-modernos esta tarefa não é fácil para os educadores, pois cada vez mais a prática do ensino transita por um espaço de saberes despolitizados e, como menciona o autor, perdido no meio de verdades abusivas, consumos frenéticos e sentidos descartáveis (WARAT, 1997, p. 69-70).

Trilhar caminho inverso parece a inevitável institucionalização simbólica da solidariedade, eis que a arte de educar no campo do Direito não consiste em lidar com om conjunto de textos normativos, mas questionar o propósito da juridicidade e que, em última instância existe para o homem, mas não alguém isolado e perdido na sua ilusão, mas um conjunto simbólico de entes solidários. Infelizmente, certas práticas do ensino e educação 
jurídicos atualmente mais contribuem para destruir certos tecidos de solidariedade social (WARAT, 1997, p. 70).

Um espaço do ensino marcado pela democracia e pela política dos direitos humanos, portanto, caminha para permitir a autonomia crítica dos estudantes de Direito, afirmando a sociedade não como um campo pré-determinado de padrões legais, mas a órbita das incertezas e diferenças sociais (WARAT, 1997, P. 72). Este é um papel crucial do ensino jurídico, qual seja, preparar os futuros profissionais para engajarem-se em práticas políticas que instituem a Democracia, capaz de lidar com as diferenças, sem discriminações, enfim, com a grandeza de compreender o outro.

Sobre a questão, mais uma vez, impõe-se a referência ao pensamento de Luiz Alberto Warat:

Para falar de democracia como uma prática política de produção do sentido, precisamos levar em conta que toda interrogação em torno da democracia é uma pergunta sobre as condições de produção do novo como sentido (não alienado) apaixonado, como uma prática que exorciza os estereótipos e ultrapassa toda determinação preliminar, arrogante e opressiva. (WARAT, 1997, p. 73).

Com efeito, reafirma-se o que já foi mencionado: o espaço do ensino e da educação no Direito é o espaço da pergunta e das interrogações sobre os próprios sentidos de democracia, ultrapassando as tentativas dogmáticas e monologizantes. Na linha de Warat, é crível sustentar a necessidade de instituir uma espécie semiologia da educação democrática, isto é, o horizonte capaz de dar conta da construção de práticas instituintes da autonomia crítica dos estudantes. Os direitos humanos como indicações de sentido direcionam-se assim para a mudança na sociedade, o caráter transformador do jurídico em uma sociedade ainda fundada em bases profundamente desiguais (WARAT, 1997, p. 77). Trata-se do objetivo de contribuir para que o próprio aluno seja capaz de construir o seu imaginário direcionado para a urgente democratização dos saberes.

É o que podemos chamar de aluno autor, autor de seu destino, sabedor das ciladas do imaginário e da instituição homogeneizante da tradição jurídica (senso comum dos juristas). Um aluno autor poderá romper com essa condição, porém, para chegar lá, será necessária uma boa dose de conhecimento da tradição que institui o imaginário do qual ele tentará escapar. Não há marco zero no conhecimento! Este é um aspecto do Direito crucial para que o aluno não seja vítima de sua própria autonomia de produção de sentidos. $\mathrm{O}$ homem que compreende encontra-se imerso em pré-compreensões, conjuntos de relações 
simbólicas que simplificam a realidade, estereótipos, normatizações, etc. Logo, cada vez mais é preciso a postura de diálogo com a tradição e ao professor incumbe indicar caminhos a serem trilhados, muitos como menciona Martin Heidegger, cotidianamente não mais percorridos pelo homem, mas isto não quer dizer que eles não existam (HEIDEGGER, 1998, p. 3).

\section{Considerações Finais}

Para tantos prognósticos sobre o fim da história, agora estamos a ver o seu extremo oposto. Uma vez que a estupefação causada por alguns fatos históricos levou muitos a conclusão de final da história (Hegel e Fukuyama, por exemplo) agora por mais que acontecimentos se sucedam, nada é permanente a ponto de gerar um marco ou ponto de começo. E assim tudo se resume em desorientação.

A crise do ensino jurídico e da educação jurídica é fruto também dessa desorientação gerneralizada e ausência de um marco permanente que possa indicar o que é certo fazer. Avolumam-se as críticas ao ensino voltado exclusivamente para concursos públicos ou provas da $\mathrm{OAB}$, pois evidentemente, tais provas e concursos não podem limitar a formação de um jurista ou constituir um marco através do qual as faculdades possam guiar o ensino a fim de alcançar seus objetivos.

O pensamento crítico necessita de um marco maior, um marco representado pela valorização da memória jurídica e tradição, para que se saiba sempre o passado, se compreenda o presente e assim, seja possível transformar o futuro, que é, enfim, o papel de todo e qualquer cidadão engajado na sua realidade social e que busca superação de seus limites.

Apenas com o ideal de um professor e aluno autores, ou em outras palavras, protagonistas do conhecimento, criadores que desenvolvem efetivamente o pensamento jurídico (e só poderão desenvolver se tiverem conhecimento e memória do passado) é que será possível substituir a produção dos atores jurídicos por autores ou atores autores. E as Academias que se restringiam a produção de atores para manutenção da estrutura de poder estabelecida e estanque poderão se tornar resultado do conteúdo humano que as distingue enquanto "Academias". E bem assim também aquele profissional, a princípio alheio da realidade e incapaz de trabalhar por mudanças na realidade a sua volta poderá quebrar o 
diagnóstico de Huxley e impor um rumo que consolide mudanças reais na comunidade em que vive.

Para isso precisa abrir os olhos para sua existência dentro de um contexto de problemas próprios, bem específicos de sua comunidade, que precisa saber identificar, deparando-se provavelmente surpreso com sua habilidade de propor soluções. Dentro do atual contexto apático da crise do ensino e educação jurídicas, essa é ainda uma postura basicamente idealista. Mas que pode levar a algum lugar diferente, e melhor.

\section{Referências Bibliográficas}

ARISTÓTELES. Ética a Nicómaco. Madrid: Cetnro de Estudios Poolíticos y Constitucionales, 1999.

BITTAR, Eduardo C. B. Estudos sobre o Ensino Jurídico: pesquisa, metodologia, diálogo e cidadania. 2a. ed. São Paulo: Atlas, 2006.

CUNHA, Paulo Ferreira da. Religião, direitos humanos e educação. Conferência de abertura do Seminário Temático Internacional "Religião e Educação", na Universidade de São Paulo, 22 de Fevereiro de 2006. Disponível em: www.defensoria.sp.gov.br/.../Religião,\%20DH\%20e\%20educação.pdf ， acesso em $14 / 04 / 2014$.

DE MASI, Domenico. O futuro chegou: modelos de vida para uma sociedade desorientada. Trad. de Marcelo Costa Sievers. Rio de Janeiro: Casa da Palavra, 2014.

DWORKIN, Ronald. Justiça para Ouriços. Coimbra: Almedina, 2011.

GADAMER, Hans-Georg. Poema y Dialogo. Trad. de Daniel Najmías y Juan Navarro. Editorial Gedisa: Barcelona, 1990.

GADAMER, Hans-Georg. La Educación es Educarse. Barcelona: Paidós, 2000.

GUEST, Sthephen. Ronald Dworkin. Rio de Janeiro: Elsevier, 2010.

FREIRE, Paulo. Pedagogia da autonomia: saberes necessários à prática educativa. São Paulo: Paz e Terra, 1996.

HEIDEGGER, Martin. Caminhos de Floresta. Lisboa: Fundação Calouste Gulbenkian, 1998.

HUXLEY, Aldous. Admirável Mundo Novo. Trad. Vidal de Oliveira. São Paulo: Globo, 2009. 
KRETSCHMANN, Angela, Org. Formação Jurídica, 1. Ano. Verbo Jurídico: Porto Alegre, 2013.

MACHADO, Antônio Alberto. Ensino Jurídico e Mudança Social. 2a . ed. São Paulo: Atlas, 2009.

RODRIGUES, Horácio Wanderlei. Roberto Lyra Filho: A importância de sua obra na história do ensino do direito brasileiro. In CERQUEIRA, Daniel Torres de; CARLINI, Angélica; ALMEIDA FILHO, José Carlos de Araújo, Org. 180 nos do ensino jurídico no Brasil. Campinas: Millennium Editora, 2007.

STRECK, Lenio Luiz. Hermenêutica Jurídica e(m) Crise: uma exploração hermenêutica da construção do Direito. $5^{\mathrm{a}}$ ed. Porto Alegre: Livraria do Advogado.

WARAT, Luiz Alberto. Epistemologia e ensino do direito: o sonho acabou. Florianópolis, Fundação Boiteux, 2004. v. II.

WARAT, Luiz Alberto. Introdução Geral ao Direito I. Porto Alegre: Ségio Antonio Fabris Editor, 1994.

WARAT, Luiz Alberto. Introdução Geral ao Direito II. Porto Alegre: Sérgio Antonio Fabris, 1995.

WARAT, Luiz Alberto. O direito e sua linguagem. 2a . versão. Porto Alegre: Fabris, 1995.

WARAT, Luiz Alberto. Introdução Geral ao Direito III. Porto Alegre: Sérgio Fabris, 1997.

(Artigo submetido em 06/06/2014 e aceito em 28/07/2014) 